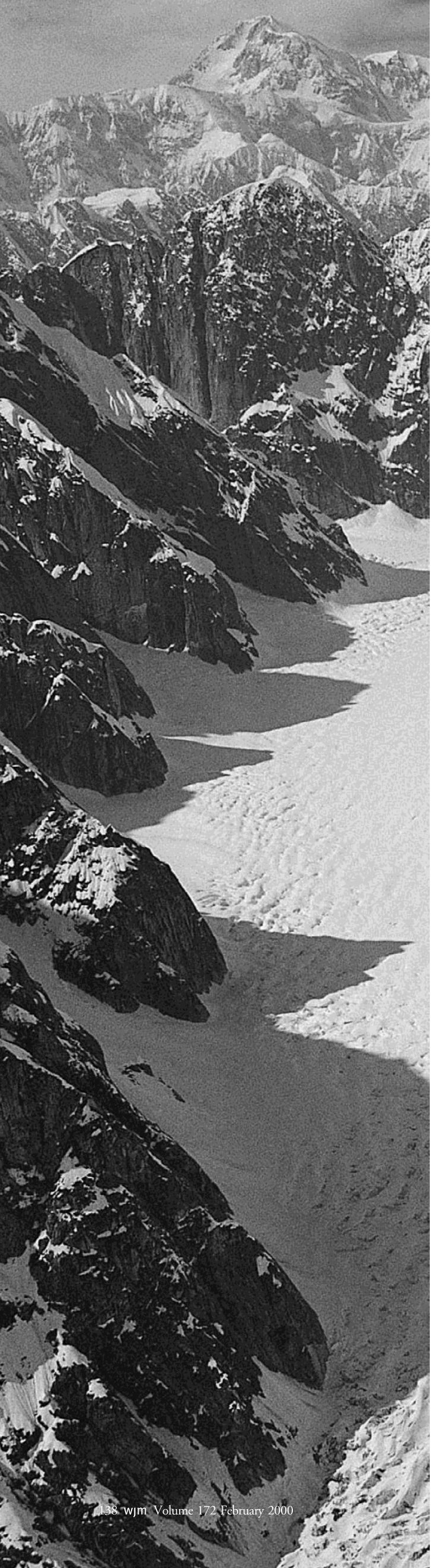

West of the Rockies

\title{
Speaker's Corner
}

\author{
Living with thalassemia
}

Living with a chronic illness has had an extensive impact on my life. Thalassemia has shaped how I live and perceive my life and it is a driving force in shaping my personality. Thalassemia and the physical challenges that accompany this disease have created my intense passion for living and a deep appreciation for health. Each day is a gift to be cherished.

Although I do not remember being diagnosed at 14 months of age, I remember being sick often as a child. Doctors' appointments, medical procedures, and surgeries are a routine part of life. Thalassemia is a high maintenance disease and, like many chronic illnesses, survival is often a fight. Therefore, I have a heightened awareness of my own mortality. I do not fixate on death, but I definitely do not plan far ahead into the future. This is not to say that I do not have a plethora of hopes and dreams.

Thalassemia has made me determined and has given me a strong will. Having a chronic illness has also taught me to be empathetic. I love people and my friends and family are my greatest treasures. My ultimate goal is to be the best person that I can be. I do not know how long I will be on this earth, but my desire is to make a difference in people's lives. Quality of life is more meaningful to me than quantity.

I always strive to live positively with thalassemia, but at times it is frustrating having to deal with a chronic illness that consumes an exorbitant amount of time with transfusions, a nightly desferal regimen, constant doctor's appointments, and various other procedures. If I could choose, I would not erase thalassemia from my life, rather I would change the way illness is managed in our society. The uphill battle for me is not always the medical dimension of the disease, but the bureaucracy that defines the health care system. Insurance is stressful for countless patients. On several occasions, I almost lost my medical insurance and more than once I have been denied coverage due to my pre-existing condition. It was medical insurance, not ill health, that almost prevented me from attending graduate school because my HMO would not offer out-ofstate coverage. Unfortunately, insurance companies, not doctors, dictate what procedures can be performed, the length of my stay in the hospital, and what medications can be used. Insurance coverage has also been a financial burden. When I worked as a preschool teacher for 6 months, my insurance payments and medical bills exceeded my income.

One of the most difficult aspects of living with thalassemia is coping with the burden it places on my family and friends. My family is extremely supportive and I believe that my thalassemia has strengthened our family dynamic, but that does not eliminate their worry and stress. Chronic illness can adversely affect the marital relationship as well as the siblings involved. There is a dire need for support services to help manage the stress placed on a family as a result of chronic illness.

With improved technology and medical advances, people with thalassemia are living longer. Therefore, consideration must be given to the new issues, such as fertility and employment, that arise from an extended lifespan. Support services and outreach programs are critical in helping patients cope with these challenges, but programs such as these are often difficult to access. With budget cuts and rising costs in health care, programs either do not exist or must be eliminated.

I hope that in the future more funds will go toward improving the management and treatment of thalassemia. A routine liver biopsy is invasive and painful. A machine has been developed, a ferritometer, that examines liver iron stores painlessly and noninvasively. Clearly, such a machine would dramatically improve patient's quality of life, yet only two ferritometers exist in the world. My hospital would like to acquire the third, but funding is a major challenge.

If I could advise clinicians, I would encourage them to make every effort to human- 
ize health care. I respect my doctors and I place much trust in them. Doctors are inundated with a large volume of patients, research, and education, thus making it easy to lose sight of the meaning of medicinehealing. Healing goes beyond prescriptions and procedures. Healing is listening, caring, answering questions, being honest, and treating the patient as a human being. Collaboration among disciplines is especially important with thalassemia because the disease affects so many physiologic systems. The patient and family must be seen as an integral part of the team and children must be encouraged to be proactive in their own care.

I must emphasize the importance of specialized thalassemia centers and centers of excellence for specific diseases in general. Thalassemia centers across the United States are few and extremely difficult to access.
Health care is decentralized, due to lack of funding, which is also problematic. Many doctors are not informed about thalassemia and the complexities of the disease. Consequently it is often up to patients to educate them. As the survival rate of patients increases, a benefit of specialized care, it is imperative that we strive for standardized and centralized thalassemia care. A multidisciplinary team approach of experts, working together, can greatly improve the quality of a patient's life.

Despite the challenges I face, I would not change the fact that I have thalassemia, I would only change the bureaucracy that underlies disease in general. I have come in contact with many amazing individuals with thalassemia who have become some of my closest friends. It is difficult to witness others fighting the same battle and it is devastating to lose loved ones to this disease. I will never get over the death of my friends, rather I have integrated the grief into my life. I carry a torch in my heart for them as I try to seize each day and live life to the fullest.

For more information, our website is: www.thalassemia. com

\section{Laurice M Compagno}

Thalassemia Community Coordinator/Child Life Specialist

Children's Hospital Oakland

Oakland, CA

Correspondence to:

Ms Compagno

Department of Hematology/Oncology

Children's Hospital Oakland

747 Fifty Second Street

Oakland, CA 94609-1809

West J Med 2000;172:138-139

\section{Om Tat Sat-Peace in the Oneness of Nature}

The gist of histories and statistics as far back as the records reach is in you this hour, and myths and tales the same

Walt Whitman

Leaves of Grass

Om Tat Sat

And now at last.

We have toiled from dawn to dawn

To find the answers in medicinal ways,

To find the cures

Through paths of pain

And journey into time's artery

We have wrapped the wounds

And watched them slowly heal,

Re-skin themselves to seal

Gradually

With words and thoughts of comforting

And often dropping to the ground

Like falling fruit

We have picked and preserved

to revive

to turn new leaves

in the serenity and tranquility of grasses yet to come. 